\title{
PERIARTICULAR REGIONAL ANALGESIA REDUCES PAIN AND HOSPITAL STAY AFTER TOTAL KNEE ARTHROPLASTY: A PROSPECTIVE, RANDOMIZED, AND DOUBLE-BLINDED CONTROLLED TRIAL
}

\author{
PULIN BIHARI DAS*, ANAND KUMAR SINGH, ARINDAM CHATTERJEE, ANURAG SINGH
}

Department of Orthopedics, Institute of Medical Sciences and SUM Hospital, Siksha '0' Anusandhan University, Bhubaneswar, Odisha, India. Email: pulin_bdas@yahoo.ca

Received: 21 April 2020, Revised and Accepted: 30 May 2020

\section{ABSTRACT}

Objective: There are multiple post-operative pain protocols for patients who undergo total knee arthroplasty (TKA). Post-operative analgesia with opioids or epidural analgesia has its side effect. We compared the duration of hospital stay, pain score, and range of motion of a control group who had no local infiltration with a group who had local infiltration analgesia following TKA.

Methods: Randomization was done in 60 patients who underwent TKA in two groups, one who did not receive and the other who received a multimodal cocktail periarticular injection containing $30 \mathrm{ml}$ of $0.5 \%$ bupivacaine, $1 \mathrm{ml}$ of $30 \mathrm{mg}$ ketorolac, $1 \mathrm{ml}$ of 1 in 1000 adrenaline, $2 \mathrm{ml}$ of 80 mg gentamycin, $5 \mathrm{ml}$ of $750 \mathrm{mg}$ cefuroxime, and rest $0.9 \%$ of normal saline. Visual analog score (VAS) for pain at rest was recorded and assessed preoperatively and postoperatively at $2,6,12,24,36 \mathrm{~h}, 2,3$, and 7 days and during an activity at $24 \mathrm{~h}, 36 \mathrm{~h}, 2$, 3, and 7 days.

Results: The patient who had received the local injection used very few analgesics over the first $24 \mathrm{~h}$ of surgery. Moreover, patients, where local infiltration was used, showed lower VAS for pain (at rest and during activity). They also showed higher VAS for patients' satisfaction.

Conclusion: Due to the reduced post-operative pain with periarticular injection analgesia, it was observed that the pain and duration of hospital stay were significantly reduced.

Keywords: Total knee arthroplasty, Local infiltration, Epidural analgesia, Multimodal cocktail periarticular injection.

(c) 2020 The Authors. Published by Innovare Academic Sciences Pvt Ltd. This is an open access article under the CC BY license (http://creativecommons. org/licenses/by/4. 0/) DOI: http://dx.doi.org/10.22159/ajpcr.2020.v13i7.37933

\section{INTRODUCTION}

Total knee arthroplasty (TKA) is regarded as the most successful operative treatment for advanced osteoarthritis of the knee joint improving quality of life [1]. Following TKA, severe post-operative pain in the first $24 \mathrm{~h}$ results in prolonged hospital stay [2]. Thus, adequate pain relief after TKA is one of the topmost priorities in the immediate post-operative period resulting in improvement of patient satisfaction, early rehabilitation and reducing hospital stay duration, and decreasing the risk of post-operative complications such as deep vein thrombosis and pneumonia [3-5].

At present, there are various methods of post-operative analgesia available, which include patient-controlled analgesia (PCA), continuous epidural pump, peripheral nerve block, local intra-articular analgesia, and continuous intra-articular infusion of analgesics, but each having its adverse effects [6-8]. The side effects of spinal/epidural anesthesia are intraoperative hypotension, post-operative headaches, neurogenic bladder, risk of infection of the spine, respiratory depression, and an increase in the total dosage of deep venous thrombosis prophylactic medicines [9]. Regional anesthesia (femoral nerve block/sciatic nerve block) is associated with infection, hematoma formation, risk of neurovascular damage, and narcotics which can lead to nausea, vomiting, respiratory depression, somnolence, urinary retention, and decreased gut motility [10-13]. Continuous intra-articular infusion of analgesics may cause considerable joint effusion and may be a source of infection. Preferably, a multimodal approach of analgesia protocol should be adopted, blocking pain at its origin to prevent complications and side effects while maintaining maximum muscle control for postoperative mobilization and physiotherapy. The use of multimodal cocktail periarticular injection (MCPI) has been reported to be effective in controlling pain, fewer adverse effects, cost-effective, and easy to use and requires no special training when compared to femoral nerve blocks or epidural anesthesia. Multiple recent studies have documented the efficacy of local infiltration of analgesics for TKA $[14,15]$.

In our study, we used a combination of a local analgesic solution consisting of a nonsteroidal anti-inflammatory drug (ketorolac), a longacting local anesthetic (bupivacaine), and antibiotics (cefuroxime and gentamycin), with adrenaline, to determine the overall effect of this MCPI on immediate post-operative pain, joint range of motion (ROM), and length of hospital stay after primary TKA.

\section{METHODS}

A prospective, randomized, and double-blinded controlled trial was conducted between June 2018 and November 2019, during which 84 consecutive patients with tri-compartmental osteoarthritis were enrolled in the study. After our study had been approved by the Institutional Ethics Committee and patients who had signed an informed consent form were considered eligible for unilateral TKA. The patients were included between 50 and 75 years of age (mean age: 65.8 years) and the range of BMI was $18.5-42.1 \mathrm{~kg} / \mathrm{m}^{2}$ (mean: $30.2 \mathrm{~kg} / \mathrm{m}^{2}$ ). Patients were excluded if they weighed more than $100 \mathrm{~kg}$, which had a major psychological illness, dependence on alcohol, narcotics, or chronic users of opioids, history of allergy to morphine or any of the drugs being injected, previous history of stroke, uncontrolled angina with prolonged QT intervals or arrhythmia, renal impairment, abnormal coagulopathy, abnormal liver function, rheumatoid arthritis, diabetes mellitus, uncontrolled hypertension, neuromuscular deficit, acute or chronic knee infection, previous knee surgery, previous patellectomy, knee with severe varus and valgus deformity ( $>$ than $20^{\circ}$ ), fixed flexion deformity $\left(>15^{\circ}\right)$, and ROM $\left(<90^{\circ}\right)$ to avoid erroneous assessment of the ROM postoperatively. 
Twenty-four patients did not meet the required criteria; hence, they were excluded from the study.

\section{Study design (randomization and blinding)}

Participants were randomized into two treatment groups: (A) Intervention group and (B) control group. SPSS Version 20.0 software (SPSS, Chicago, Illinois) was used to create a randomization table by a study coordinator (an independent hospital pharmacist), who prepared and provided the medication for periarticular injection in identical disposable syringes tagged with code numbers. He did not have any involvement in surgery or patient care. A simple random table was used for generating the cards which had a random number sequence and was in sealed envelopes. Odd/even numbers were used by the study coordinator for the allocation of the enrolled patients to Group A/B which was random and double-blinded. The surgeon, nurses, and pharmacists who collected post-operative patients' data were blinded to treatment group allocation. The release of the blinding codes was done subsequently in the data analysis stage.

Spinal anesthesia was given by an anesthetist to all the patients with morphine $(0.3 \mathrm{mg})$ and $3 \mathrm{~mL}$ of $0.5 \%$ heavy bupivacaine. No epidural anesthesia was used in our patients. All patients were given preoperatively pregabalin $150 \mathrm{mg}$, intravenous infusion of magnesium at the rate of $50 \mathrm{mg} / \mathrm{kg}$ over $30 \mathrm{~min}(\max 3 \mathrm{~g})$ then $15 \mathrm{mg} / \mathrm{kg} / \mathrm{h}$ till the end of the surgery, and $2 \mathrm{~g}$ IV of tranexamic acid as a bolus. Cefuroxime (1.5 g) was given for prophylaxis $30 \mathrm{~min}$ before starting the operation. Midazolam (1-2 mg) was given to anxious patients during the operation. A Foleys catheter and tourniquet were used in all our patients. A single surgeon performed all the operations. For all the surgeries, the approach was through an anterior midline incision and standard medial parapatellar arthrotomy. Cemented posterior stabilized total knee prostheses were used in both groups (Zimmer Nexgen: USA). The patella was resurfaced in all cases. Insertion of a non-suction drain was done before the closure of the wound and removal was done after $24 \mathrm{~h}$. Removal of the Foleys catheter was done on post-operative day 1 along with the starting of isometric exercises and ROM. The ambulation of the patients was done with a walker as per their tolerance.

\section{Intervention}

Group A (local infiltration group)

A cocktail of $60 \mathrm{ml}$ was prepared under aseptic measure using $30 \mathrm{ml}$ of $0.5 \%$ bupivacaine, $1 \mathrm{ml}$ of cefuroxime, and rest $0.9 \%$ of normal saline (Table 1).

After lavage of the surgical site, equal doses of the mixture were injected into each of the following eight sites (Fig. 1):

(1) The posterior capsule (Fig. 2), (2) the medial capsular incision (Fig. 3), (3) the lateral capsular incision (Fig. 4), (4) the subcutaneous tissue along both edges of the incision (Fig. 5), (5) the medial collateral ligament, (6) the lateral collateral ligament, (7) the retinacular tissues, and (8) the quadriceps mechanism.

Excessive infiltration was avoided in the area around the common peroneal nerve. Infiltration was done through an 18 gauges needle and was infiltrated before the tourniquet is released. The posterior capsule was injected after the bone cut was done and the remainder of capsular infiltration was done after the final component was implanted and while bone cement was polymerizing.

\section{Group B (control group)}

Infiltration of an equal amount of $0.9 \%$ normal saline solution was done in the control group as in the intervention group in the same areas and similar techniques.

Both the groups received as follows:

1. Injection amoxicillin (1.2 g) I.V. twice daily

2. Injection cefuroxime (1.5 g) I.V. twice daily
Table 1: Composition of multimodal cocktail injection

\begin{tabular}{llll}
\hline S. No. & Drug & Dose (conc.) & Volume \\
\hline 1. & Bupivacaine & $0.5 \%$ & $30 \mathrm{ml}$ \\
2. & Ketorolac & $30 \mathrm{mg}$ & $1 \mathrm{ml}$ \\
3. & Adrenaline & $1: 1000$ & $1 \mathrm{ml}$ \\
4. & Gentamycin & $80 \mathrm{mg}$ & $2 \mathrm{ml}$ \\
5. & Cefuroxime & $750 \mathrm{mg}$ & $5 \mathrm{ml}$ \\
6. & Normal saline & $0.9 \%$ & $21 \mathrm{ml}$ \\
Total & & & $60 \mathrm{ml}$ \\
\hline
\end{tabular}

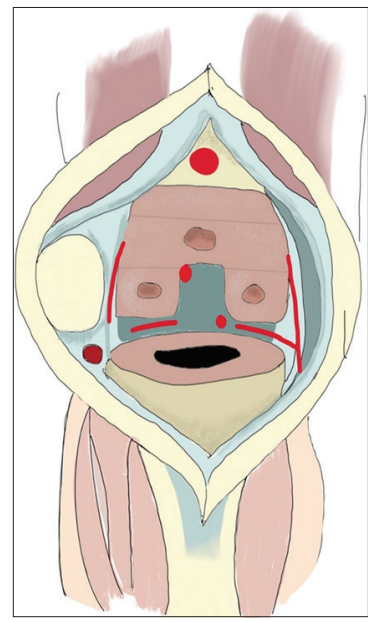

Fig. 1: The eight regions of the knee (marked in red) having increased pain receptors

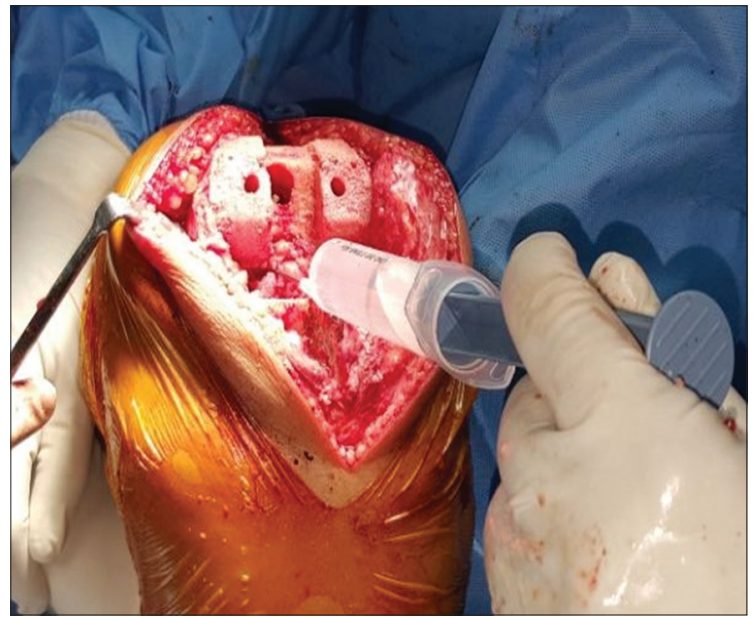

Fig. 2: Multimodal cocktail periarticular injection being infiltrated in the posterior capsule

3. Injection paracetamol ( $1 \mathrm{~g}) \mathrm{I} . \mathrm{V}$. thrice daily

4. Injection diclofenac $(75 \mathrm{mg})$ I.V. twice daily

5. Topical cold therapy was given thrice daily until the discharge of the patient

6. For the first $72 \mathrm{~h}$, a sequential compression device was used

7. Low molecular weight heparin $(0.3 \mathrm{ml}-0.4 \mathrm{ml})$ was given subcutaneously daily until discharge for the prevention of deep vein thrombosis.

\section{Outcome measures}

The follow-up of the patients was done postoperatively and assessed daily during the hospital stay. The recording of the scores was done in a double-blind fashion to make the reviewer uninformed of the side of infiltration as also the patient. 


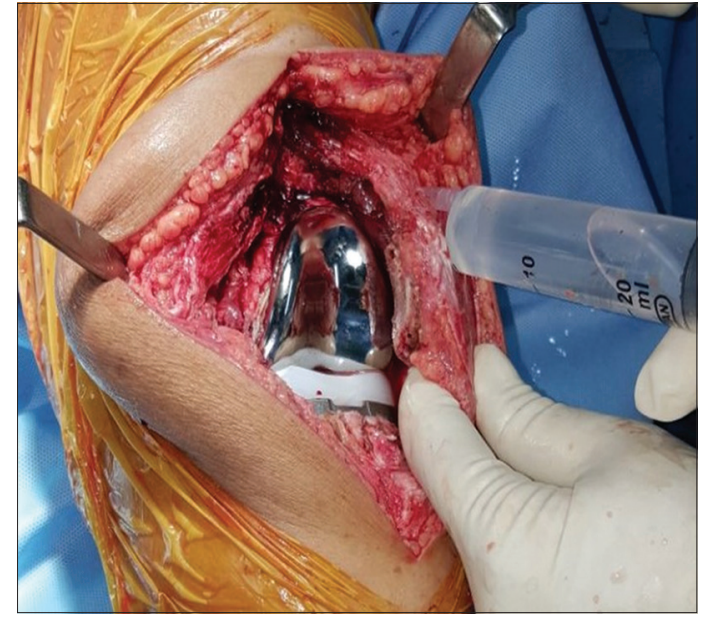

Fig. 3: Multimodal cocktail periarticular injection being infiltrated in the medial capsule

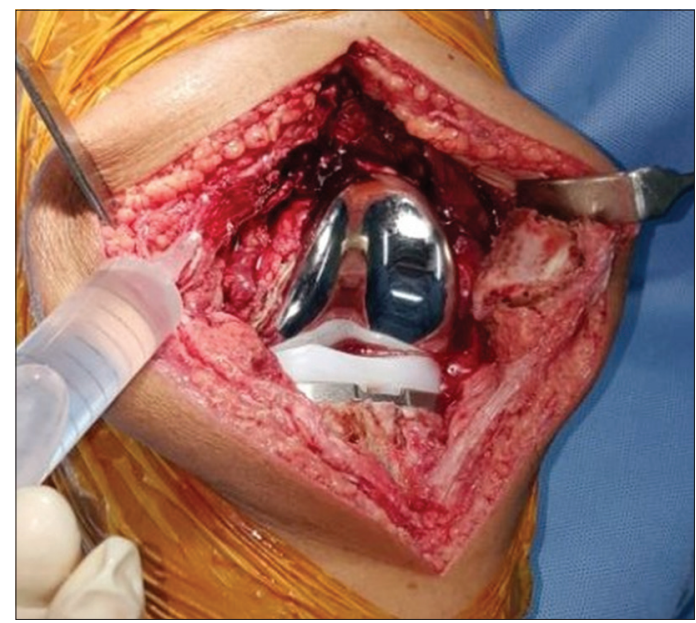

Fig. 4: Multimodal cocktail periarticular injection being infiltrated in the lateral capsule

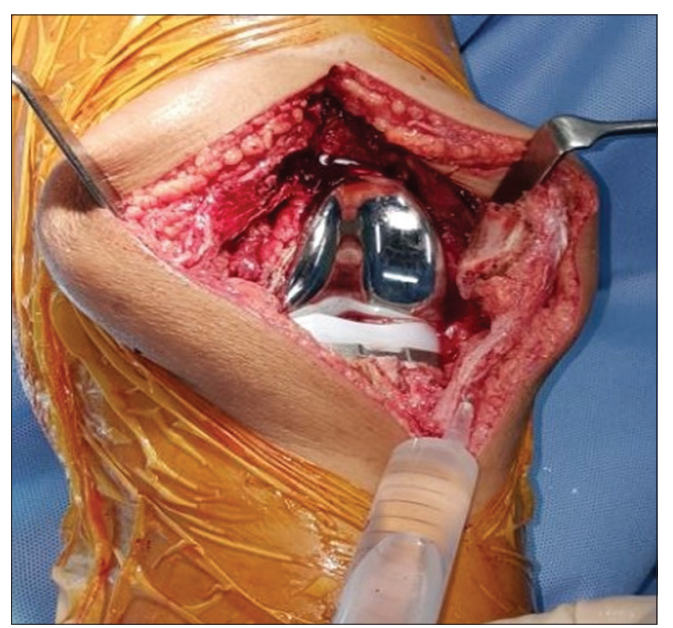

Fig. 5: Multimodal cocktail periarticular injection being infiltrated in the medial aspect of subcutaneous tissue

Primary outcome measure

Pain relief

The collection of data was done by the investigators who were familiar with the assessment methods and those who were not a participant in the study. Visual analog score (VAS) was used to assess the severity of pre-operative pain both at rest and during activity. Assessment of postoperative pain was done through VAS at $2,6,12,24$, and $36 \mathrm{~h}$ and on $2^{\text {nd }}, 3^{\text {rd }}$, and $7^{\text {th }}$ days at rest and $24 \mathrm{~h}, 36 \mathrm{~h}, 2^{\text {nd }}, 3^{\text {rd }}$, and $7^{\text {th }}$ days during activity. Pre-operative and post-operative ROM was measured on $1^{\text {st }}$, $2^{\text {nd }}, 3^{\text {rd }}$, and $7^{\text {th }}$ days.

The total amount of paracetamol and diclofenac consumed was recorded for post-operative day 3. The monitoring of patients was done for the adverse effects of bupivacaine, for example, cardiac and central nervous system toxicity. The presence of nausea and vomiting, pruritus, or urinary retention, and somnolence were also determined. The complications which occurred during the trial were recorded, especially surgical site infections, wound condition, and opioid-related complications.

\section{Secondary outcome measures}

Duration of hospital stay

The calculation was done from the day of admission and discharge of the patient. Patients were discharged when they fulfilled the following discharge criteria:

- $\quad$ Mild pain (VAS< 3 ) controlled by oral analgesics

- Independent use of the toilets

- Weight-bearing with walker

- No surgical complications.

\section{ROM}

The ROM was assessed by the physiotherapist, who measured the postoperative knee flexion with the help of goniometer on $1^{\text {st }}, 2^{\text {nd }}, 3^{\text {rd }}$, and $7^{\text {th }}$ days. Follow-up of all the patients was done on 1, 3, 6, and 12 months postoperatively. Pre-operative and post-operative knee scores were recorded at $1,3,6$, and 12 months.

\section{Statistical analysis}

The mean \pm SD for continuous variables and the frequency and percentage for categorical variables was calculated. Processing of the data was done through SPSS statistical software (version 20.0) (SPSS Inc., USA). Univariate analysis was performed by Chi-square or Fisher's exact test to compare the distribution between categorical data. The Mann-Whitney U-test was done to correlate the non-parametric significant data between two independent samples. $\mathrm{p} \leq 0.05$ was considered to be statistically significant.

\section{RESULTS}

In our study, we found that the pain score was significantly lower $1^{\text {st }}$ post-operative day in the locally infiltrated group. There was a significant pain score difference on the $2^{\text {nd }}$ and $3^{\text {rd }}$ post-operative days. The decrease in the average maximum pain score in the intervention group was significant as compared to the control group (Figs. 6 and 7). There was no significant difference in the wound complication rate between these groups. There was a significant difference in the ROM until post-operative day 7 and in the mean duration of hospital stay (Figs. 8 and 9).

\section{DISCUSSION}

Post-operative pain following TKA is a major problem. The pain is usually due to trauma to soft tissues or bone or hyperperfusion after tourniquet release. Adequate pain relief is essential for early rehabilitation postoperatively. Surgical trauma causes peripheral and central sensitization due to a rise in the excitability of spinal neurons. This causes hypersensitivity and decreases the pain threshold at the operative site. Adrenaline helps in keeping the infiltrated drugs locally and prevents drug toxicity through its vasoconstriction properties. Bupivacaine blocks afferent peripheral nociceptive activity $[4,14]$. Ketorolac blocks inflammatory cytokines and reduces peripheral sensitization of neurons. Tranexamic acid reduces post-operative bleeding, and pregabalin reduces post-operative pain by binding to $\alpha_{2} \delta$ unit of presynaptic Ca channel, reducing the release of substance P, 5HT, 


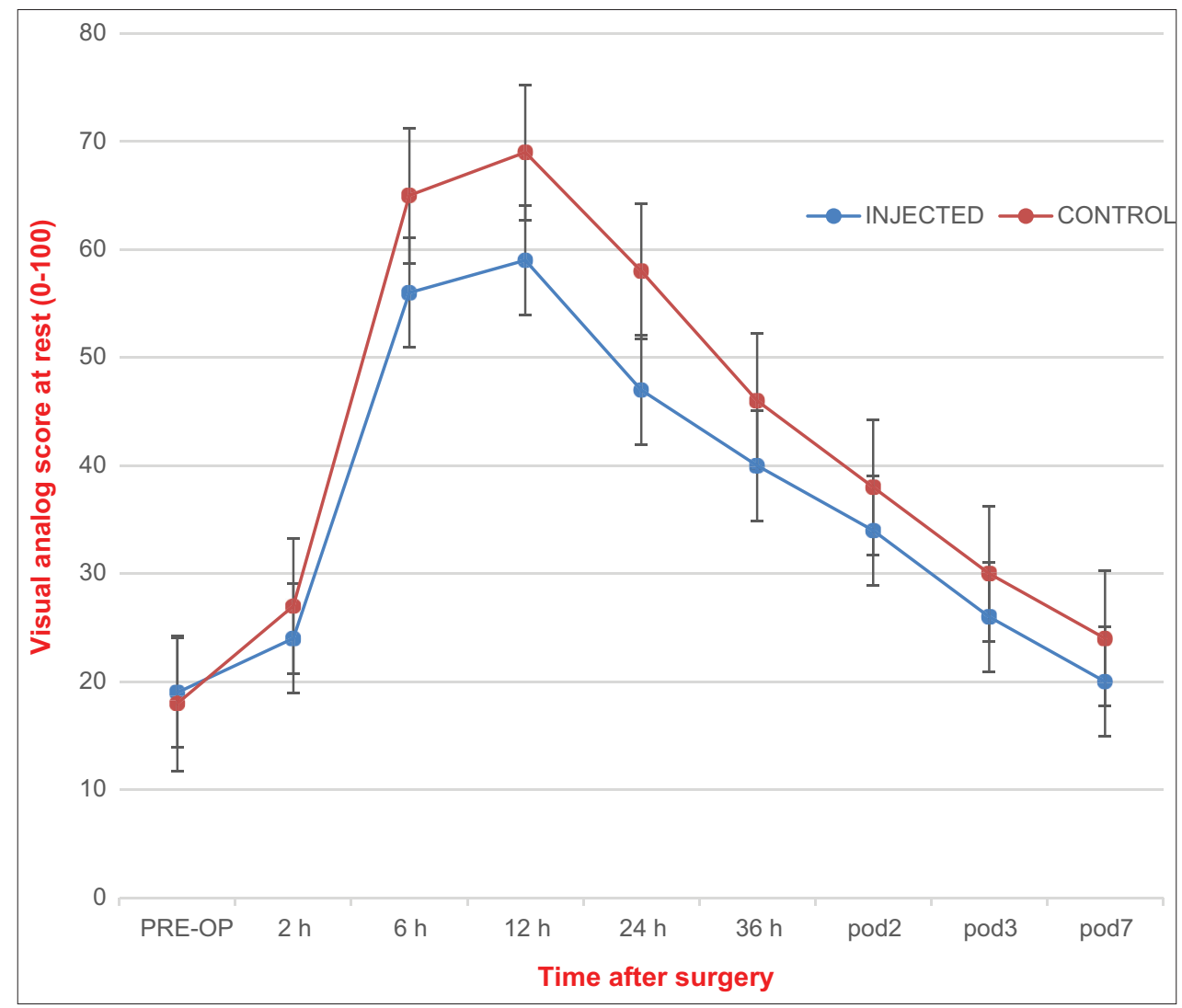

Fig. 6: Pain at rest as measured by a visual analog score in patients who received multimodal cocktail periarticular analgesia (30 patients in the injected group) as compared to (30 patients in the control group). Pre-op: Pre-operative, POD: Post-operative day

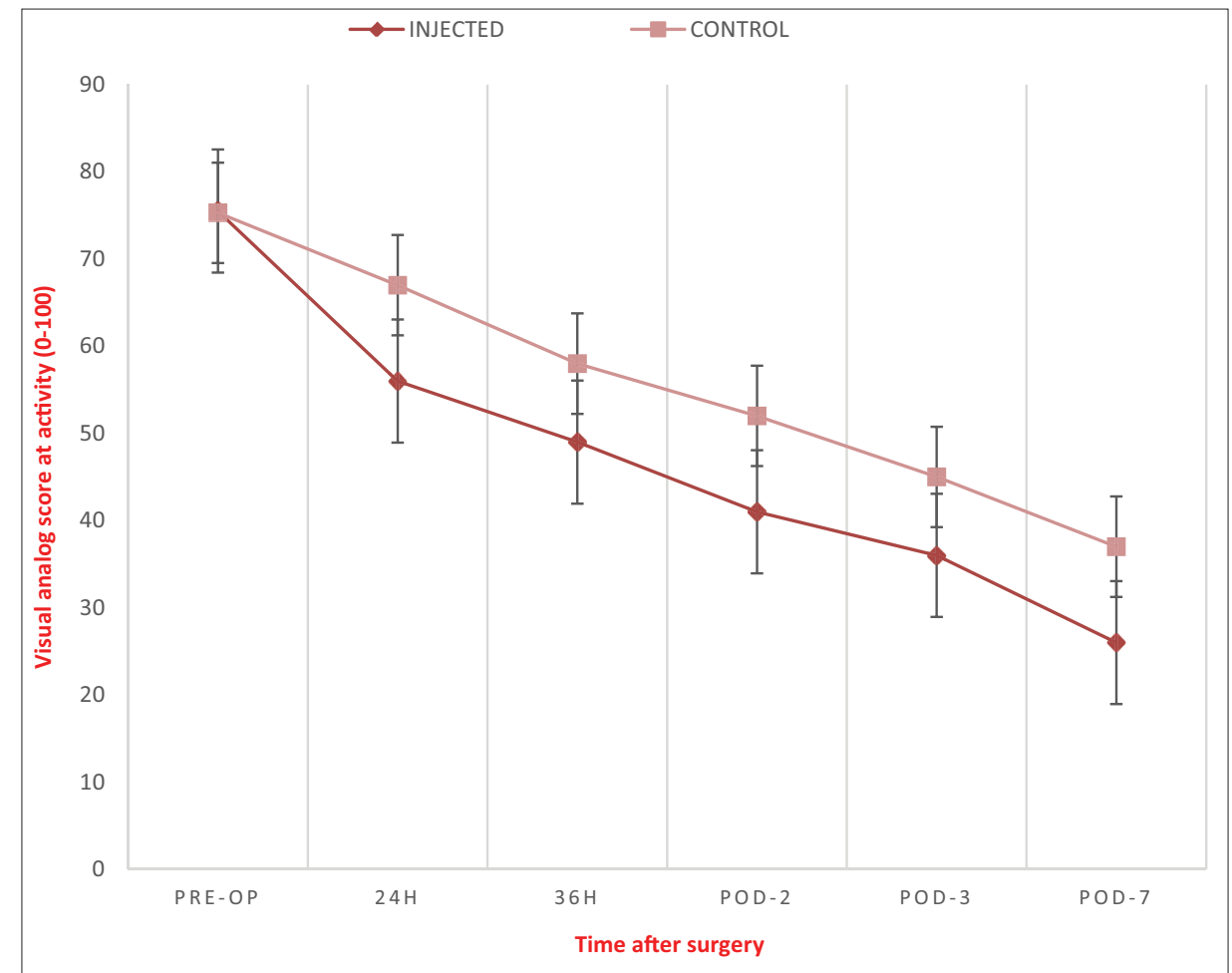

Fig. 7: Pain during activity as measured by a visual analog score in patients who received multimodal cocktail periarticular analgesia (30 patients in the injected group) as compared to (30 patients in the control group). Pre-op: Pre-operative, POD: Post-operative day

noradrenaline, dopamine, and by attenuating postsynaptic excitability. Magnesium reduces post-operative pain by its properties of N-methyl- d-aspartate (NMDA) receptor antagonist and calcium channel blocker. Magnesium also prevents the induction of central sensitization due to 


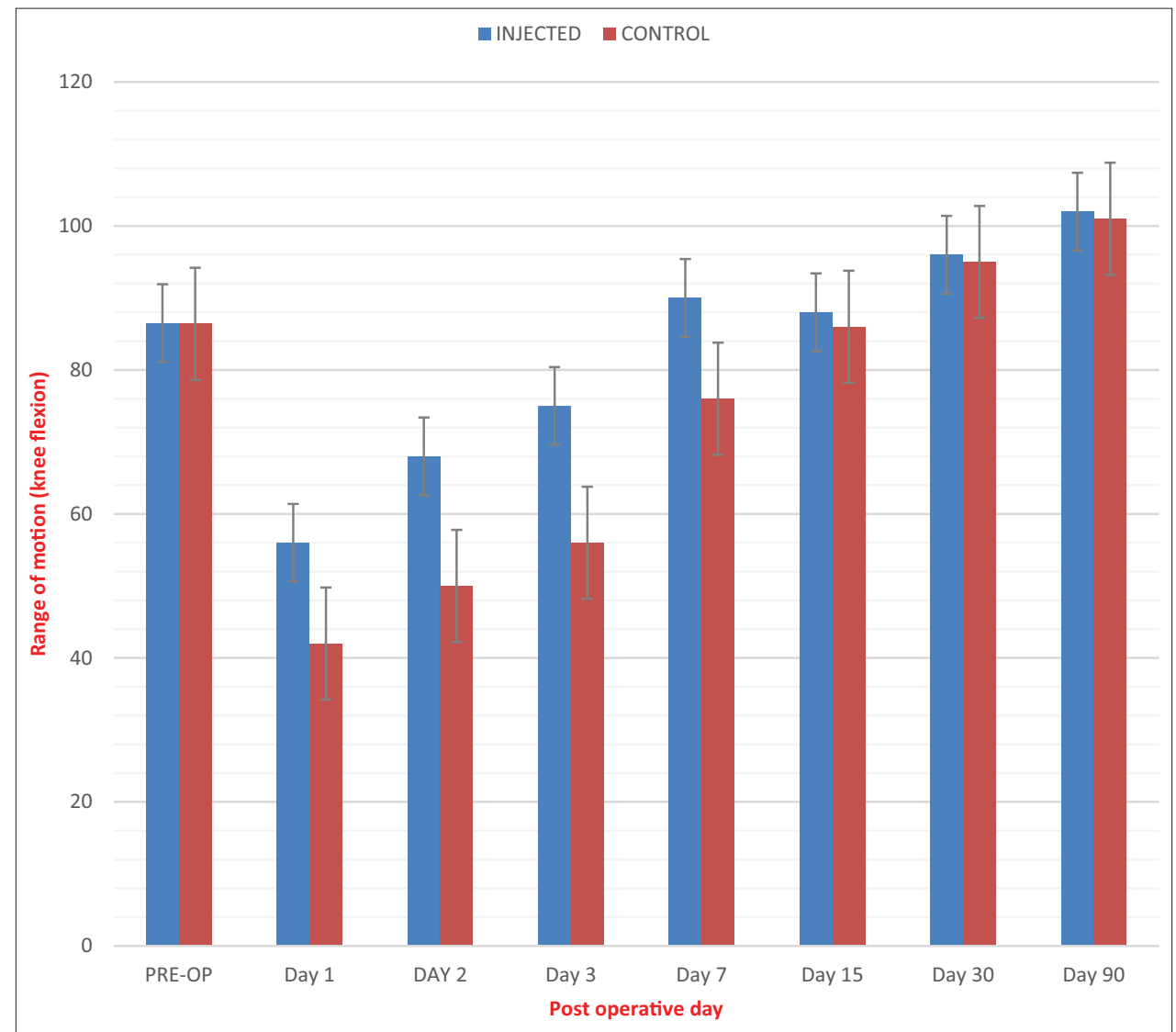

Fig. 8: Range of motion (knee flexion) in patients who received multimodal periarticular analgesia (30 patients in the injected group) as compared to (30 patients in the control group). Pre-op: Pre-operative

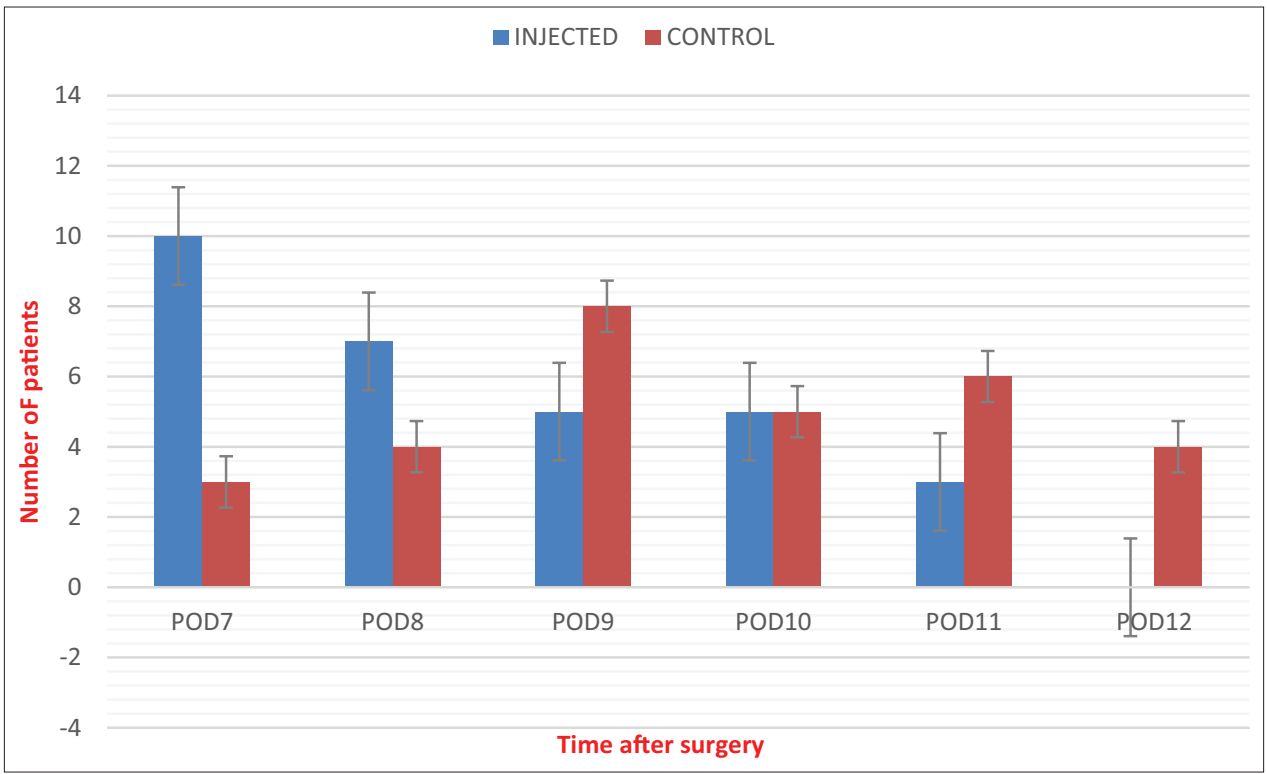

Fig. 9: Duration of hospital stay in patients who received multimodal periarticular analgesia (30 patients in the injected group) as compared to 30 patients in the control group. POD: Post-operative day

peripheral nociceptive stimulation and abolishes hypersensitivity by its antagonism of the NMDA receptor $[16,17]$.

Busch et al. studied the efficacy of local perioperative injection with ropivacaine, ketorolac, epinephrine, epimorphine, and normal saline in TKA patients which resulted in a lower pain score and less consumption of analgesics at $12 \mathrm{~h}$ after the operation as compared to a control group [14]. Badner et al., in their study of the effects of intraoperative intra-articular bupivacaine-epinephrine injection in TKA patients, showed a decrease in the consumption of post-operative analgesics with an increase in ROM at discharge in the infiltrated patients, but no significant relief of pain was noted on the addition of morphine to a bupivacaine injection [18]. Vendittoli et al. showed a decrease in the use of PCA at $48 \mathrm{~h}$ with negligible adverse effects in patients who 
underwent intraoperative periarticular infiltration with adrenaline, ketorolac, ropivacaine, and ropivacaine injection $(150 \mathrm{mg})$ on day 1 post-surgery [19]. Parvataneni et al. reported that local perioperative infiltration with a cocktail of epinephrine, morphine sulfate, $0.5 \%$ bupivacaine, cefuroxime, methylprednisolone acetate, and $0.9 \%$ normal saline in joint replacement surgeries resulted in increased satisfaction scores, decreased pain score at $72 \mathrm{~h}$, and reduced hospital stay [20]. Pang et al. showed the inclusion of triamcinolone acetonide to the periarticular injection after TKA resulted in immediate and short-term benefits in pain relief and rehabilitation. There was no increase in the risk of infection in this study [21]. Lamplot et al. reported a decrease in the duration of hospital stay in the infiltrated group in comparison to the PCA group [22]. Lombardi et al. studied the efficacy of soft tissue and intra-articular bupivacaine, morphine, and epinephrine injection in patients who underwent primary TKAs and reported a reduction in the need for rescue doses of narcotic medicines as well as significant pain relief, but nothing significant improvement was found in terms of length of hospital stay and ROM [23]. Mullaji et al. studied the effects of an intra-articular analgesic cocktail containing bupivacaine, methylprednisolone, fentanyl, and cefuroxime in patients undergoing bilateral computer-assisted TKA showing significant improvement in pain scores and active flexion up to 4 weeks with quadriceps recovery up to 2 weeks [24].

In our study, the mean VAS in the injected group at rest was $38.25 \pm 14.78$ and during activity was $41.62 \pm 11.59$ suggesting significant pain reliefs as compared to the mean VAS of $44.62 \pm 17.62$ at rest and $51.8 \pm 11.56$ during activity in the control group. The mean ROM in our study was $82.14 \pm 16.41$ in the injected group, whereas $72.29 \pm 23.17$ in the control group. Hence, faster rehabilitation was seen in the injected group. There was a substantial reduction in the duration of hospital stay in the injected group in comparison to the control group in our study.

\section{CONCLUSION}

Intraoperative periarticular analgesic injection significantly reduces post-operative pain and reduces the requirement of post-operative analgesics with no apparent risk, following TKA. We observed a lesser length of hospital stay in local analgesia injected group than those who were not injected. The local analgesia infiltrated groups were able to bear weight much earlier than the non-infiltrated group.

\section{AUTHORS' CONTRIBUTIONS}

PBD conducted the clinical study, AKS and AC helped PBD in the data analysis and writing the draft copy of the paper. All authors approved the manuscript.

\section{CONFLICTS OF INTEREST}

The author declares that there are no conflicts of interest.

\section{AUTHORS' FUNDING}

The author received no specific funding for this work.

\section{REFERENCES}

1. Ng FY, Ng JK, Chiu KY, Yan CH, Chan CW. Multimodal periarticular injection vs continuous femoral nerve block after total knee arthroplasty: A prospective, crossover, randomized clinical trial. J Arthroplasty 2012:27:11234-8.

2. Wylde V, Rooker J, Halliday L, Blom A. Acute postoperative pain at rest after hip and knee arthroplasty: Severity, sensory qualities and impact on sleep. Orthop Traumatol Surg Res 2011;97:139-44.

3. Peters CL, Shirley B, Erickson J. The effect of a new multimodal perioperative anesthetic regimen on postoperative pain, side effects, rehabilitation, and length of hospital stay after total joint arthroplasty. J Arthroplasty 2006;21:132-8.
4. Horlocker TT, Kopp SL, Pagnano MW, Hebl JR. Analgesia for total hip and knee arthroplasty: A multimodal pathway featuring peripheral nerve block. J Am Acad Orthop Surg 2006;14:126-35.

5. Parvataneni HK, Shah VP, Howard H, Cole N, Ranawat AS, Ranawat CS. Controlling pain after total hip and knee arthroplasty using a multimodal protocol with local periarticular injections: A prospective randomized study. J Arthroplasty 2007;22:33-8.

6. Ilfeld BM, Mariano ER, Madison SJ, Loland VJ, Sandhu NS, Suresh PJ, et al. Continuous femoral versus posterior lumbar plexus nerve blocks for analgesia after hip arthroplasty: A randomized, controlled study. Anesth Analg 2011;113:897-903.

7. Pagnano MW, Hebl J, Horlocker T. Assuring a painless total hip arthroplasty: A multimodal approach emphasizing peripheral nerve blocks. J Arthroplasty 2006;21;80-4.

8. Shep D, Khanwelkar C, Gade P, Karad S. A randomized controlled trial of curcumin and diclofenac combination in knee osteoarthritis. Int $\mathrm{J}$ Curr Pharm Sci 2019;11:111-4.

9. Venkatraman R, Sandhiya R. Evaluation of efficacy of epidural butorphanol tartrate for postoperative analgesia. Int J Pharm Pharm Sci 2014;7:52-4

10. Sharma S, Iorio R, Specht LM, Davies Lepie S, Healy WL. Complications of femoral nerve block for total knee arthroplasty. Clin Orthop Relat Res 2010;468:135-40.

11. Horlocker TT, Cabanela ME, Wedel DJ. Does postoperative epidural analgesia increase the risk of peroneal nerve palsy after total knee arthroplasty? Anesth Analg 1994;79:495-500.

12. Horlocker TT, Wedel DJ. Neuraxial block and low-molecular-weight heparin: Balancing perioperative analgesia and thromboprophylaxis. Reg Anesth Pain Med 1998;23:164-77.

13. Horlocker TT, Hebl JR, Kinney MA, Cabanela ME. Opioid-free analgesia following total knee arthroplasty--a multimodal approach using continuous lumbar plexus (psoas compartment) block, acetaminophen, and ketorolac. Reg Anesth Pain Med 2002;27:105-8.

14. Busch CA, Shore BJ, Bhandari R, Ganapathy S, MacDonald SJ, Bourne RB, et al. Efficacy of periarticular multimodal drug injection in total knee arthroplasty. A randomized trial. J Bone Joint Surg Am 2006;88:959-63.

15. Hebl JR, Kopp SL, Ali MH, Horlocker TT, Dilger JA, Lennon RL, et al. A comprehensive anesthesia protocol that emphasizes peripheral nerve blockade for total knee and total hip arthroplasty. J Bone Joint Surg Am 2005;87 Suppl 2:63-70.

16. Vidya VS, Felicita AS. Efficacy of pharmacological agents in the treatment of temporomandibular joint disorder: A systematic review. Int J Pharm Pharm Sci 2015;7:54-8.

17. Dubé L, Granry JC. The therapeutic use of magnesium in anesthesiology, intensive care and emergency medicine: A review. Can J Anaesth 2003:50:732-46.

18. Badner NH, Bourne RB, Rorabeck CH, MacDonald SJ, Doyle JA. Intra-articular injection of bupivacaine in knee-replacement operations. Results of use for analgesia and for preemptive blockade. J Bone Joint Surg Am 1996;78:734-8

19. Vendittoli PA, Makinen P, Drolet P, Lavigne M, Fallaha M, Guertin MC, et al. A multimodal analgesia protocol for total knee arthroplasty. A randomized, controlled study. J Bone Joint Surg Am 2006;88:282-9.

20. Parvataneni HK, Ranawat AS, Ranawat CS. The use of local periarticular injections in the management of postoperative pain after total hip and knee replacement: A multimodal approach. Instr Course Lect 2007;56:125-31.

21. Pang HN, Lo NN, Yang KY, Chong HC, Yeo SJ. Peri-articular steroid injection improves the outcome after unicondylar knee replacement: A prospective, randomised controlled trial with a two-year follow-up. J Bone Joint Surg Br 2008;90:738-44.

22. Lamplot JD, Wagner ER, Manning DW. Multimodal pain management in total knee arthroplasty: A prospective randomized controlled trial. J Arthroplasty 2014;29:329-34.

23. Lombardi AV Jr., Berend KR, Mallory TH, Dodds KL, Adams JB. Soft tissue and intra-articular injection of bupivacaine, epinephrine, and morphine has a beneficial effect after total knee arthroplasty. Clin Orthop 2004:428:125-30.

24. Mullaji A, Kanna R, Shetty GM, Chavda V, Singh DP. Efficacy of periarticular injection of bupivacaine, fentanyl, and methylprednisolone in total knee arthroplasty: A prospective, randomized trial. J Arthroplasty 2010;25:851-7. 